\title{
Incidences of obesity and extreme obesity among US adults: findings from the 2009 Behavioral Risk Factor Surveillance System
}

\author{
Liping Pan ${ }^{1 *}$, David S Freedman ${ }^{1}$, Cathleen Gillespie ${ }^{2}$, Sohyun Park ${ }^{1}$ and Bettylou Sherry ${ }^{1}$
}

\begin{abstract}
Background: No recent national studies have provided incidence data for obesity, nor have they examined the association between incidence and selected risk factors. The purpose of this study is to examine the incidence of obesity (body mass index [BMI] $\geq 30.0 \mathrm{~kg} / \mathrm{m}^{2}$ ) and extreme obesity (BMI $\geq 40.0 \mathrm{~kg} / \mathrm{m}^{2}$ ) among US adults and to determine variations across socio-demographic characteristics and behavioral factors.

Methods: We used a weighted sample of 401,587 US adults from the 2009 Behavioral Risk Factor Surveillance System. Incidence calculations were based on respondent's height and current and previous weights. Logistic regression was used to examine associations between incidence and selected socio-demographic characteristics and behavioral factors.
\end{abstract}

Results: The overall crude incidences of obesity and extreme obesity in 2009 were 4\% and $0.7 \%$ per year, respectively. In our multivariable analyses that controlled for baseline body mass index, the incidences of obesity and extreme obesity decreased significantly with increasing levels of education. Incidences were significantly higher among young adults, women, and adults who did not participate in any leisure-time physical activity. Incidence was lowest among non-Hispanic whites.

Conclusions: The high incidence of obesity underscores the importance of implementing effective policy and environmental strategies in the general population. Given the significant variations in incidence within the subgroups, public health officials should prioritize younger adults, women, minorities, and adults with lower education as the targets for these efforts.

Keywords: Body Mass Index, Obesity, Incidence, Risk Prediction

\section{Background}

The prevalence of obesity among adults has more than doubled in the past three decades, and obesity continues to be a public health concern [1,2]. One of the objectives of Healthy People 2020 is to reduce the proportion of adults who are obese [3]. It is well established that obesity is related to reduced quality of life, increased risk for premature death, and increased risk for many chronic diseases, including coronary heart disease, hypertension, stroke, Type 2 diabetes, and certain types

\footnotetext{
* Correspondence: Lpan@cdc.gov

'Division of Nutrition, Physical Activity, and Obesity, National Center for Chronic Disease Prevention and Health Promotion, Centers for Disease Control and Prevention, Atlanta, GA, USA

Full list of author information is available at the end of the article
}

of cancer $[4,5]$. Obesity is also associated with increased health care costs. It has been estimated that obesity was associated with almost $10 \%$ of annual medical spending and that obesity-related medical costs reached \$147 billion in 2008 [6].

Numerous studies have examined the prevalence of obesity and extreme obesity, with findings indicating that more than one-third of US adults were obese during 2007-2008 [2,7]. Prevalence data are very useful to identify high risk populations for interventions; however, prevalence focuses on people who have been obese or extremely obese for amounts of time, as well as those who have recently attained such status. Prevalence indicates the magnitude of the problem of obesity, whereas incidence conveys information about the rate of

\section{C) Biomed Central}


developing it. Incidence identifies those who become obese or extremely obese over a certain period of time. Incidence data are valuable because they enable elucidation of the characteristics of the incident cases during the study period, thus identifying those at high risk for becoming obese to target for prevention efforts. Reducing obesity prevalence requires interventions to help those who are already obese maintain or lose weight as well as interventions to prevent new cases from becoming obese. Several studies have examined the incidence of obesity between the 1950s and the early 2000s and identified demographic characteristics associated with the incidence [8-10]. However, no recent national studies have provided incidence data, nor have they examined the association between incidence and selected risk factors. Because various factors, such as age, sex, race, physical activity, and smoking, have all been associated with the prevalence of obesity $[2,11,12]$, we assumed that these factors also may be related to the incidence of obesity. The purpose of our study is to examine the incidences of obesity and extreme obesity, socio-demographic characteristics and behavioral factors associated with these incidences, and to examine changes in BMI categories over a one-year period.

\section{Methods \\ Data}

We used data from the 2009 Behavioral Risk Factor Surveillance System (BRFSS). BRFSS is an ongoing, statebased, telephone interview survey conducted annually by the Centers for Disease Control and Prevention and state health departments. The survey is based on a multistage cluster design that uses random-digit dialing to select a sample that represents the civilian noninstitutionalized adult population in each of the 50 states, the District of Columbia, and three US territories. Post-stratification weights are used to adjust for nonresponse, noncoverage, and disproportionate selection of population, and to produce demographic distributions that correspond closely to the state population. Detailed descriptions of its sampling design and methods have been previously published $[13,14]$.

We used a weighted sample of 432,607 US adults. We excluded subjects who reported a current or previous weight $\geq 500$ pounds $(\mathrm{n}=107)$ or a height $\geq 7$ feet or $<$ 3 feet $(\mathrm{n}=32)$, subjects who were missing data for height $(\mathrm{n}=5,599)$ or for current or previous weight ( $\mathrm{n}$ $=22,103$ ), subjects who had a current or previous body mass index (BMI, calculated from weight $[\mathrm{kg}] /$ height $\left.\left[\mathrm{m}^{2}\right]\right)$ less than the minimum BMI value calculated from measured heights and weights of the third and fourth National Health and Nutrition Examination Survey participants (BMI $<11.7 \mathrm{~kg} / \mathrm{m}^{2}, \mathrm{n}=55$ ), women who reported that they were pregnant $(n=2,480)$, and women aged 18 to 44 years who did not report pregnancy status $(\mathrm{n}=644)$, which yielded a final sample size of 401,587 .

Self-reported weight and height and incidence calculation Obesity and extreme obesity were defined as having a BMI $\geq 30.0 \mathrm{~kg} / \mathrm{m}^{2}$ and $\geq 40.0 \mathrm{~kg} / \mathrm{m}^{2}$, respectively [4]. Respondents were asked, "About how much do you weigh without shoes?", "How much did you weigh a year ago?", and "About how tall are you without shoes?" Current BMI was calculated from self-reported current weight and height. BMI in previous year was calculated from self-reported weight in previous year and current self-reported height. Weight changes were calculated by subtracting respondents' current weight from their previous weight.

We calculated the incidences of obesity and extreme obesity in various groups. The numerator was defined as adults who became obese or extremely obese between 2008 and 2009. The populations in the denominators were defined as those who were at risk of becoming obese (BMI 11.7-29.9 $\mathrm{kg} / \mathrm{m}^{2}$ ) or extremely obese (BMI $11.7-39.9 \mathrm{~kg} / \mathrm{m}^{2}$ ) in 2008 . Incidences of obesity and extreme obesity were then calculated by dividing the numbers of adults who developed obesity or extreme obesity during the one-year period by the numbers of adults who were at risk. Among those included in the final sample, 284,122 respondents were at risk of becoming obese, and 382,713 respondents were at risk of becoming extremely obese. To fully understand weight changes, we also examined weight loss between 2008 and 2009.

\section{Socio-demographic characteristics and behavioral factors}

For socio-demographic characteristics, we used four age groups (18-29, 30-49, 50-69, and $\geq 70$ years), three racial/ethnic groups (non-Hispanic white, non-Hispanic black, and Hispanic), four levels of education (less than high school, high school, some college, and college graduate), and five regions (US territories composite and four US census regions: Northeast, Midwest, South, and West). For the 2008 baseline BMI, three categories $\left(11.7-24.9 \mathrm{~kg} / \mathrm{m}^{2}, 25.0-27.4 \mathrm{~kg} / \mathrm{m}^{2}\right.$, and $\left.27.5-29.9 \mathrm{~kg} / \mathrm{m}^{2}\right)$ were used to estimate adjusted incidence of obesity, and five categories $\left(11.7-29.9 \mathrm{~kg} / \mathrm{m}^{2}, 30-32.4 \mathrm{~kg} / \mathrm{m}^{2}, 32.5-\right.$ $34.9 \mathrm{~kg} / \mathrm{m}^{2}, 35.0-37.4 \mathrm{~kg} / \mathrm{m}^{2}, 37.5-39.9 \mathrm{~kg} / \mathrm{m}^{2}$ ) were used for adjusted incidence of extreme obesity to ensure adequate sample size.

For behavioral factors, we examined four areas: physical activity, fruit and vegetable consumption, smoking, and alcohol drinking. We used the leisure-time physical activity question, "During the past month, other than your regular job, did you participate in any physical activities or exercise such as running, calisthenics, golf, 
gardening, or walking for exercise?", as a proxy for physical activity. We created a dichotomous variable to measure fruit and vegetable consumption: $<5$ times/day versus $\geq 5$ times/day. Fruit and vegetable consumption was based on a six-item frequency screener concerning fruit juices, fruit, green salad, nonfried potatoes, carrots, and other vegetables. We measured smoking status by three groups: nonsmoker, former smoker, and current smoker. We also included three alcohol drinking categories: no drinking, any drinking (adults who have had at least one drink of any alcoholic beverage during the past month but are not heavy drinkers), and heavy drinking (adult men having $>2$ drinks/day and adult women having $>1$ drink/day).

For our analyses, we used 2009 data on current weight status, socio-demographic and behavioral variables, as well as weight change based on recall of weight a year ago. To examine the association of incidence with behavioral factors, we made the assumption that respondents' health behaviors did not change between 2008 and 2009, and their current behaviors were used as a proxy to predict incidence.

\section{Statistical analyses}

All statistical analyses were carried out using SAS-Callable SUDAAN (Version 9.2; SAS Institute, Cary, North Carolina). The variances for the estimates were adjusted to the BRFSS complex sampling design, including stratification, primary sampling unit, and clustering.

We used descriptive statistics to examine the characteristics of the study sample and mean weight changes. We used t-tests to compare the differences in mean weight changes between groups and polynomial contrasts to test for linear trends in mean weight changes across level of education and baseline BMI. We conducted logistic regression to estimate the adjusted incidences of obesity and extreme obesity and to identify factors associated with incidences. Because of missing data on covariates, the models included 253,183 respondents who were at risk for obesity and 342,284 respondents who were at risk for extreme obesity. The covariates included in the models were age, sex, race/ ethnicity, level of education, region, physical activity, fruit and vegetable consumption, smoking, alcohol drinking, and baseline BMI. We calculated predictive margins (adjusted incidence) for various groups, adjusting for all other variables in the model. Predictive margin is a type of direct standardization in which the predicted values from the logistic regression model are averaged over the covariate distribution of the population, allowing control for differences in covariate distribution between groups [15]. We calculated risk ratios by comparing the predictive margins for respondents across groups with certain socio-demographic and behavioral characteristics. In addition, we used pairwise contrast to examine the differences in adjusted incidence across groups and defined a linear contrast to test the presence of a linear trend across baseline BMI in each of the logistic regression models. To control for the inflated type 1 error rate due to our large sample size, we used $\mathrm{p}<0.01$ to define statistical significance.

\section{Results}

\section{Description of respondents}

The characteristics of our analytic sample are described in Table 1. Although our analytic sample included about $40 \%$ men and $60 \%$ women, it was weighted to represent the age, sex, and race distribution of the state's adult population. Approximately $69 \%$ of our weighted sample were non-Hispanic whites, $42 \%$ were 50 years or older, $35 \%$ had at least a college education, and $36 \%$ resided in the South.

\section{Mean weight changes}

Among all the adults included in this study, the mean weight change between 2008 and 2009 was about a one pound weight loss $(95 \%$ confidence interval $[\mathrm{CI}]=-1.2$, $-0.9 \mathrm{lb})$. Among those who were at risk of becoming extremely obese, the mean weight loss was $0.2 \mathrm{lb}(-0.3$,

\section{Table 1 Descriptive statistics by socio-demographic characteristics, Behavioral Risk Factor Surveillance} System: United States, 2009

\begin{tabular}{|c|c|c|c|c|}
\hline \multirow[t]{2}{*}{ Characteristic/behavioral factor } & \multicolumn{2}{|c|}{$\begin{array}{l}\text { Men } \\
(N=158,770)\end{array}$} & \multicolumn{2}{|c|}{$\begin{array}{l}\text { Women } \\
(N=242,817)\end{array}$} \\
\hline & $\mathrm{n}$ & $\%^{a}$ & $\mathrm{n}$ & $\%^{a}$ \\
\hline \multicolumn{5}{|l|}{ Age group (years) } \\
\hline $18-29$ & 10,884 & 20.3 & 14,175 & 17.4 \\
\hline $30-49$ & 45,485 & 39.6 & 67,503 & 37.3 \\
\hline $50-69$ & 69,901 & 29.6 & 101,696 & 30.6 \\
\hline$\geq 70$ & 31,842 & 10.2 & 58,064 & 14.3 \\
\hline \multicolumn{5}{|l|}{ Race/ethnicity } \\
\hline White, non-Hispanic & 127,416 & 68.2 & 190,829 & 69.8 \\
\hline Black, non-Hispanic & 10,064 & 9.1 & 20,847 & 10.4 \\
\hline Hispanic & 10,019 & 14.4 & 16,343 & 13.3 \\
\hline \multicolumn{5}{|l|}{ Educational level } \\
\hline$<$ High school & 14,261 & 10.5 & 21,997 & 9.6 \\
\hline High school & 45,951 & 28.3 & 73,647 & 27.8 \\
\hline Some college & 39,137 & 25.1 & 68,924 & 28.4 \\
\hline College graduate & 59,176 & 35.9 & 77,931 & 34.1 \\
\hline \multicolumn{5}{|l|}{ Census region } \\
\hline Northeast & 28,747 & 17.7 & 43,762 & 18.0 \\
\hline Midwest & 38,326 & 21.8 & 57,265 & 22.0 \\
\hline South & 45,803 & 36.0 & 77,513 & 36.2 \\
\hline West & 43,258 & 23.2 & 59,690 & 22.4 \\
\hline Territory & 2636 & 1.2 & 4587 & 1.3 \\
\hline
\end{tabular}

a Weighted percentage; the percentages in each category may not add up to $100 \%$ because of missing data 
-0.1). However, the most weight loss occurred among those who were previously obese. Among adults who were at risk of becoming obese, there was a mean weight gain of $1.5 \mathrm{lb}(1.4,1.6)$. Among those who were at risk of becoming obese or extremely obese, the respondents with higher education levels and baseline BMI had significantly lower mean weight gain $(\mathrm{p}<0.01)$, whereas young adults, women, non-Hispanic blacks, and Hispanics had significantly higher mean weight gain $(\mathrm{p}<0.01)$ during the previous year (Table 2).

To examine the distribution of weight change in this population, we reported both weight gain and weight loss. Some respondents experienced weight gain between 2008 and 2009 (Table 3). For example, 35.8\% of the underweight (baseline BMI $11.7-18.4 \mathrm{~kg} / \mathrm{m}^{2}$ ) adults achieved normal weight status, and $9.5 \%$ of the

Table 2 Mean weight changes among adults aged $\geq 18$ years who were at risk for obesity ${ }^{a}$ and extreme obesity ${ }^{b}$ between 2008 and 2009, by socio-demographic characteristic, Behavioral Risk Factor Surveillance System: United States, 2009

\begin{tabular}{|c|c|c|c|c|}
\hline \multirow[b]{2}{*}{ Characteristic } & \multicolumn{2}{|c|}{$\begin{array}{l}\text { At risk for obesity } \\
\left(B M I 11.7-29.9 \mathrm{~kg} / \mathrm{m}^{2}\right) \\
(\mathrm{N}=284,122)\end{array}$} & \multicolumn{2}{|c|}{$\begin{array}{l}\text { At risk for extreme obesity } \\
\left(\mathrm{BMI} 11.7-39.9 \mathrm{~kg} / \mathrm{m}^{2}\right) \\
(\mathrm{N}=382,713)\end{array}$} \\
\hline & Mean change $(\mathrm{lb})^{c}$ & $(95 \% \mathrm{Cl})$ & Mean change $(\mathrm{lb})^{c}$ & $(95 \% \mathrm{Cl})$ \\
\hline Overall & 1.5 & $(1.4,1.6)$ & -0.2 & $(-0.3,-0.1)$ \\
\hline \multicolumn{5}{|l|}{ Age group (years) } \\
\hline $18-29$ & 3.9 & $(3.5,4.2)$ & 2.3 & $(1.9,2.6)$ \\
\hline $30-49$ & 1.7 & $(1.6,1.9)$ & 0.1 & $(-0.1,0.2)$ \\
\hline $50-69$ & 0.6 & $(0.5,0.7)$ & -1.2 & $(-1.3,-1.1)$ \\
\hline$\geq 70$ & -1.0 & $(-1.2,-0.9)$ & -2.3 & $(-2.4,-2.1)$ \\
\hline \multicolumn{5}{|l|}{ Sex } \\
\hline Women & 1.6 & $(1.5,1.8)$ & 0.2 & $(0.1,0.3)$ \\
\hline Men & 1.3 & $(1.1,1.5)$ & -0.5 & $(-0.7,-0.4)$ \\
\hline \multicolumn{5}{|l|}{ Race/ethnicity } \\
\hline White, non-Hispanic & 0.9 & $(0.8,1.0)$ & -0.6 & $(-0.7,-0.5)$ \\
\hline Black, non-Hispanic & 3.7 & $(3.1,4.2)$ & 1.2 & $(0.7,1.6)$ \\
\hline Hispanic & 3.1 & $(2.7,3.5)$ & 1.0 & $(0.6,1.4)$ \\
\hline \multicolumn{5}{|l|}{ Educational level } \\
\hline$<$ High school & 3.6 & $(3.2,4.0)$ & 1.4 & $(1.0,1.8)$ \\
\hline High school & 2.2 & $(2.0,2.4)$ & 0.3 & $(0.1,0.5)$ \\
\hline Some college & 1.5 & $(1.4,1.7)$ & -0.3 & $(-0.5,-0.2)$ \\
\hline College graduate & 0.4 & $(0.3,0.5)$ & -0.8 & $(-1.0,-0.7)$ \\
\hline \multicolumn{5}{|l|}{ Census region } \\
\hline Northeast & 1.4 & $(1.2,1.7)$ & -0.2 & $(-0.4,0.1)$ \\
\hline Midwest & 1.4 & $(1.2,1.5)$ & -0.3 & $(-0.5,-0.1)$ \\
\hline South & 1.7 & $(1.5,1.9)$ & -0.1 & $(-0.2,0.1)$ \\
\hline West & 1.3 & $(1.1,1.5)$ & -0.2 & $(-0.4,0.0)$ \\
\hline Territory & 1.9 & $(1.3,2.4)$ & 0.3 & $(-0.3,0.9)$ \\
\hline \multicolumn{5}{|l|}{ Baseline BMI $\left(\mathrm{kg} / \mathrm{m}^{2}\right)$} \\
\hline $11.7-24.9$ & 3.0 & $(2.8,3.1)$ & $-d$ & $-d$ \\
\hline $25.0-27.4$ & 0.6 & $(0.5,0.8)$ & - & - \\
\hline $27.5-29.9$ & -1.2 & $(-1.4,-0.9)$ & - & - \\
\hline $11.7-29.9$ & - e & $-{ }^{e}$ & 1.5 & $(1.4,1.6)$ \\
\hline $30.0-32.4$ & - & - & -3.0 & $(-3.3,-2.7)$ \\
\hline $32.5-34.9$ & - & - & -5.5 & $(-6.0,-5.0)$ \\
\hline $35.0-37.4$ & - & - & -7.3 & $(-7.9,-6.6)$ \\
\hline $37.5-39.9$ & - & - & -10.1 & $(-11.2,-9.1)$ \\
\hline
\end{tabular}

at risk for obesity: BMI $11.7-29.9 \mathrm{~kg} / \mathrm{m}^{2}$

${ }^{b}$ At risk for extreme obesity: BMI $11.7-39.9 \mathrm{~kg} / \mathrm{m}^{2}$

c Weighted mean

d Not applicable; we combined these three baseline BMI categories for adults who were at risk for extreme obesity to ensure adequate sample size

e Not applicable; we used three baseline BMI categories (as indicted in the table) for adults who were at risk for obesity 
Table 3 Change of BMI status between 2008 and 2009 among adults aged $\geq 18$ years, Behavioral Risk Factor Surveillance System

\begin{tabular}{|c|c|c|c|c|c|}
\hline \multirow[b]{2}{*}{2008 BMI $\left(\mathrm{kg} / \mathrm{m}^{2}\right)$} & \multicolumn{5}{|c|}{$\begin{array}{c}2009 \mathrm{BMI}\left(\mathrm{kg} / \mathrm{m}^{2}\right) \\
\%{ }^{\mathrm{a}} \text { (standard error [SE]) }\end{array}$} \\
\hline & $11.7-18.4$ & $18.5-24.9$ & $25.0-29.9$ & $30.0-39.9$ & $\geq 40.0$ \\
\hline $11.7-18.4$ & $62.0(1.37)$ & $35.8(1.37)$ & $1.6(0.32)$ & $0.5(0.13)$ & $0.02(0.02)$ \\
\hline $18.5-24.9$ & $0.9(0.05)$ & $88.8(0.19)$ & $9.5(0.18)$ & $0.7(0.06)$ & $0.04(0.01)$ \\
\hline $25.0-29.9$ & $0.1(0.01)$ & $9.0(0.17)$ & $83.4(0.22)$ & $7.5(0.16)$ & $0.1(0.03)$ \\
\hline $30.0-39.9$ & $0.1(0.02)$ & $1.2(0.07)$ & $16.7(0.26)$ & $79.3(0.29)$ & $2.7(0.13)$ \\
\hline$\geq 40.0$ & $0.1(0.08)$ & $0.3(0.04)$ & $2.4(0.22)$ & $29.6(0.71)$ & $67.6(0.72)$ \\
\hline
\end{tabular}

${ }^{a}$ Weighted percentage, the row percentages sum to $100 \%$

previously normal weight (baseline BMI $18.5-24.9 \mathrm{~kg} /$ $\mathrm{m}^{2}$ ) adults became overweight. During the same time, some other adults experienced weight loss and moved from higher to lower BMI categories (Table 3). For example, $16.7 \%$ of the previously obese (baseline BMI $30.0-39.9 \mathrm{~kg} / \mathrm{m}^{2}$ ) adults became overweight, and $29.6 \%$ of the previously extremely obese (baseline BMI $\geq 40.0$ $\mathrm{kg} / \mathrm{m}^{2}$ ) adults became obese in 2009.

\section{Factors associated with incidence of obesity and extreme obesity}

The overall crude incidences of obesity and extreme obesity in 2009 were $4.0 \%(3.9 \%, 4.2 \%)$ and $0.7 \%(0.6 \%$, $0.8 \%)$ per year, respectively. In our multivariable analyses, the strongest factor associated with both the incidence of obesity and extreme obesity was baseline BMI. As the baseline BMI increased, the incidences of obesity and extreme obesity significantly increased $(\mathrm{p}<0.01$ for trend test across BMI) (Table 4).

However, even after controlling for baseline BMI, we found that the incidences of obesity and extreme obesity varied by socio-demographic characteristics (Table 4). These incidences were significantly higher among younger age groups. The incidences of obesity and extreme obesity among adults aged $\geq 70$ years was more than $75 \%$ lower than the incidences among those aged $18-29$ years $(1.5 \%$ versus $6.4 \%$, and $0.2 \%$ versus $1.2 \%$, respectively, $\mathrm{p}<0.01)$. Women had $50 \%$ or higher incidences of obesity and extreme obesity than did men ( $5.4 \%$ versus $3.2 \%$, and $0.9 \%$ versus $0.6 \%$, respectively, $\mathrm{p}$ $<0.01)$. Non-Hispanic whites and college graduates had lower incidences of obesity and extreme obesity. Adults in the South had a significantly higher incidence of extreme obesity than adults in the Northeast, West, and territories $(\mathrm{p}<0.01)$, and adults living in the Midwest had a higher incidence of extreme obesity than adults living in the territories $(\mathrm{p}<0.01)$ (Table 4).

After adjusting for other variables in the model, participating in any leisure-time physical activity was significantly associated with a $30 \%$ reduction in incidence of obesity and a $40 \%$ reduction in incidence of extreme obesity (Table 4). In comparison to nonsmokers, former and current smokers who were at risk for obesity had a $40 \%$ higher risk of becoming obese during the past year. Compared with no consumption, any consumption of alcohol during past month was associated with a $10 \%$ decreased risk for obesity and a $20 \%$ decreased risk for extreme obesity.

\section{Discussion}

We found that the incidences of obesity and extreme obesity rose with increasing baseline BMI. The incidences of obesity and extreme obesity were higher among younger adults, women, non-Hispanic blacks and Hispanics, adults with lower levels of education, and adults who did not participate in any leisure-time physical activity. Adults who did not drink any alcoholic beverages had higher incidences than those who had at least one drink but were not heavy drinkers during the past month. Many, but not all, of these associations agree with the results of studies based on the prevalence of obesity. We also found that a considerable proportion of obese and extremely obese adults lost weight between 2008 and 2009 and moved to lower BMI categories. The mean weight loss increased as baseline BMI increased.

Baseline BMI was the most significant indicator for both obesity and extreme obesity incidence. This result was not surprising because adults with high baseline BMI would have had to gain less weight to become obese or extremely obese. This finding indicates that prevention of further weight gain should be the first step of obesity control, especially among "at-risk" adults with high baseline BMI, because obesity-related morbidities increase with increasing BMI $[4,5]$.

The incidences of obesity and extreme obesity were highest among adults aged 18 to 29 years, indicating that young adults are more likely to develop a weight problem even though the prevalence of obesity is lowest among this group [7]. Obesity is associated with morbidity and with the leading causes of death in the United States $[4,5]$. The risk for obesity-related chronic diseases will be significantly increased among young adults, and 
Table 4 Adjusted incidence ${ }^{a}$ and risk ratios of obesity ${ }^{b}$ and extreme obesity ${ }^{c}$ among adults aged $\geq 18$ years, by selected socio-demographic characteristics and behavioral factors, Behavioral Risk Facto Surveillance System: United States, 2009

\begin{tabular}{|c|c|c|c|c|c|c|}
\hline \multirow{3}{*}{ Characteristic/behavioral factor } & \multicolumn{3}{|c|}{ Obesity $\left(\mathrm{BMI} \geq 30.0 \mathrm{~kg} / \mathrm{m}^{2}\right)$} & \multicolumn{3}{|c|}{ Extreme obesity $\left(\mathrm{BMI} \geq 40.0 \mathrm{~kg} / \mathrm{m}^{2}\right)$} \\
\hline & \multirow{2}{*}{$\begin{array}{l}\text { Adjusted incidence } \\
\% \text { (SE) }\end{array}$} & \multicolumn{2}{|c|}{ Risk ratio } & \multirow{2}{*}{$\begin{array}{l}\text { Adjusted incidence } \\
\% \text { (SE) }\end{array}$} & \multicolumn{2}{|c|}{ Risk ratio } \\
\hline & & Ratio & $(95 \% \mathrm{Cl})$ & & Ratio & $(95 \% \mathrm{Cl})$ \\
\hline \multicolumn{7}{|l|}{ Age group (years) } \\
\hline $18-29$ & $6.4(0.37)$ & $1.0^{d}$ & & $1.2(0.15)$ & 1.0 & \\
\hline $30-49$ & $4.8(0.16)^{\mathrm{e}}$ & 0.8 & $(0.7,0.9)$ & $0.9(0.06)$ & 0.7 & $(0.6,1.0)$ \\
\hline $50-69$ & $3.3(0.11)$ & 0.5 & $(0.5,0.6)$ & $0.5(0.03)$ & 0.4 & $(0.3,0.6)$ \\
\hline$\geq 70$ & $1.5(0.10)$ & 0.2 & $(0.2,0.3)$ & $0.2(0.04)$ & 0.2 & $(0.1,0.3)$ \\
\hline \multicolumn{7}{|l|}{ Sex } \\
\hline Women & $5.4(0.14)$ & 1.0 & & $0.9(0.05)$ & 1.0 & \\
\hline Men & $3.2(0.12)$ & 0.6 & $(0.5,0.6)$ & $0.6(0.05)$ & 0.6 & $(0.5,0.8)$ \\
\hline \multicolumn{7}{|l|}{ Race/ethnicity } \\
\hline White, non-Hispanic & $3.4(0.09)$ & 1.0 & & $0.6(0.04)$ & 1.0 & \\
\hline Black, non-Hispanic & $6.0(0.41)$ & 1.8 & $(1.5,2.0)$ & $0.8(0.08)$ & 1.3 & $(1.1,1.6)$ \\
\hline Hispanic & $5.5(0.37)$ & 1.6 & $(1.4,1.9)$ & $1.0(0.15)$ & 1.5 & $(1.1,2.1)$ \\
\hline \multicolumn{7}{|l|}{ Educational level } \\
\hline$<$ High school & $5.1(0.34)$ & 1.0 & & $0.9(0.12)$ & 1.0 & \\
\hline High school & $4.8(0.20)$ & 0.9 & $(0.8,1.1)$ & $0.8(0.07)$ & 0.9 & $(0.6,1.2)$ \\
\hline Some college & $4.2(0.17)$ & 0.8 & $(0.7,1.0)$ & $0.7(0.06)$ & 0.7 & $(0.5,1.0)$ \\
\hline College graduate & $2.9(0.13)$ & 0.6 & $(0.5,0.7)$ & $0.5(0.05)$ & 0.5 & $(0.4,0.7)$ \\
\hline \multicolumn{7}{|l|}{ Census region } \\
\hline Northeast & $4.1(0.22)$ & 1.0 & & $0.6(0.07)$ & 1.0 & \\
\hline Midwest & $4.1(0.16)$ & 1.0 & $(0.9,1.1)$ & $0.7(0.06)$ & 1.1 & $(0.8,1.4)$ \\
\hline South & $4.3(0.17)$ & 1.1 & $(0.9,1.2)$ & $0.9(0.07)$ & 1.4 & $(1.1,1.8)$ \\
\hline West & $3.8(0.21)$ & 0.9 & $(0.8,1.1)$ & $0.6(0.08)$ & 0.9 & $(0.7,1.3)$ \\
\hline Territory & $3.4(0.42)$ & 0.8 & $(0.6,1.1)$ & $0.3(0.10)$ & 0.5 & $(0.3,1.0)$ \\
\hline \multicolumn{7}{|l|}{ Leisure-time physical activity } \\
\hline No & $5.1(0.19)$ & 1.0 & & $1.0(0.07)$ & 1.0 & \\
\hline Yes & $3.7(0.11)$ & 0.7 & $(0.7,0.8)$ & $0.6(0.04)$ & 0.6 & $(0.5,0.7)$ \\
\hline \multicolumn{7}{|c|}{$\geq 5$ times of fruits and vegetables per day } \\
\hline No & $4.1(0.11)$ & 1.0 & & $0.7(0.04)$ & 1.0 & \\
\hline Yes & $3.9(0.18)$ & 0.9 & $(0.8,1.0)$ & $0.6(0.07)$ & 0.9 & $(0.7,1.1)$ \\
\hline \multicolumn{7}{|l|}{ Smoking } \\
\hline Nonsmoker & $3.5(0.11)$ & 1.0 & & $0.7(0.05)$ & 1.0 & \\
\hline Former smoker & $5.0(0.20)$ & 1.4 & $(1.3,1.6)$ & $0.8(0.07)$ & 1.2 & $(1.0,1.5)$ \\
\hline Current smoker & $4.8(0.23)$ & 1.4 & $(1.2,1.6)$ & $0.7(0.08)$ & 1.0 & $(0.8,1.3)$ \\
\hline \multicolumn{7}{|l|}{ Alcohol drinking } \\
\hline No drinking & $4.4(0.14)$ & 1.0 & & $0.8(0.05)$ & 1.0 & \\
\hline Any drinking & $3.8(0.14)$ & 0.9 & $(0.8,1.0)$ & $0.6(0.05)$ & 0.8 & $(0.6,0.9)$ \\
\hline Heavy drinking & $3.8(0.40)$ & 0.9 & $(0.7,1.1)$ & $0.7(0.20)$ & 0.9 & $(0.5,1.6)$ \\
\hline \multicolumn{7}{|l|}{ Baseline BMI $\left(\mathrm{kg} / \mathrm{m}^{2}\right)$} \\
\hline $11.7-24.9$ & $0.7(0.06)$ & 1.0 & & $-{ }^{f}$ & $-{ }^{f}$ & \\
\hline $25.0-27.4$ & $3.7(0.19)$ & 5.5 & $(4.4,6.8)$ & - & - & - \\
\hline $27.5-29.9$ & $14.4(0.37)$ & 21.6 & $(17.8,26.2)$ & - & - & - \\
\hline $11.7-29.9$ & -9 & -9 & & $0.1(0.02)$ & 1.0 & \\
\hline $30.0-32.4$ & - & - & - & $0.5(0.10)$ & 6.6 & $(3.6,12.1)$ \\
\hline $32.5-34.9$ & - & - & - & $1.0(0.14)$ & 13.9 & $(8.3,23.5)$ \\
\hline $35.0-37.4$ & - & - & - & $3.4(0.28)$ & 48.5 & $(30.2,77.9)$ \\
\hline $37.5-39.9$ & - & - & - & $11.4(0.85)$ & 161.6 & $(101.0,258.7)$ \\
\hline
\end{tabular}

\footnotetext{
${ }^{\text {a }}$ Predictive margins adjusted for baseline BMI and all other socio-demographic characteristics and behavioral factors in the model

b Obesity: $\mathrm{BMI} \geq 30.0 \mathrm{~kg} / \mathrm{m}^{2}$

c Extreme obesity: $\mathrm{BMI} \geq 40.0 \mathrm{~kg} / \mathrm{m}^{2}$

${ }^{\mathrm{d}}$ Reference group

${ }^{e} p<0.01$ for pairwise contrast to test for the difference between the bolded estimate and the estimate for the reference group

${ }^{\mathrm{f}}$ Not applicable; we combined these three baseline BMI categories for adults who were at risk for extreme obesity to ensure adequate sample size

${ }^{9}$ Not applicable; we used three baseline BMI categories (as indicted in the table) for adults who were at risk for obesity
} 
their quality of life will be considerably diminished throughout the rest of their lives once they become obese. Therefore, obesity prevention efforts are likely to have the biggest impact on young adults in their 20 s. Consistent with previous studies [16,17], we found that women were more likely to develop obesity than were men. These findings suggest that young adults, particularly young women, are important groups to focus on to prevent obesity.

Non-Hispanic blacks, Hispanics, and adults with lower levels of education had higher incidences of obesity and extreme obesity. Behavioral, cultural, and environmental factors may have contributed to the high incidences. According to one study, both non-Hispanic black women and Hispanic women are more satisfied with their body size than are non-Hispanic white women; those who are satisfied with their body size are less likely to try to lose weight [18]. Evidence also suggests that black, Hispanic, and lower-income neighborhoods have fewer chain supermarkets and produce stores and less access to physical activity facilities; this limited access may negatively impact diet and physical activity levels [19].

Using the same data source, the 2009 BRFSS, a previous study indicated that the South and Midwest had higher prevalences of obesity than the Northeast and West [7]. Our study shows that the South has a significantly higher incidence of extreme obesity than the Northeast, West, and the territories. The South may be a geographic region that warrants extra obesity prevention efforts.

Certain behavioral factors were associated with the incidences of obesity and extreme obesity even after controlling for baseline BMI and socio-demographic characteristics. Participating in any leisure-time physical activity was associated with decreased risks of developing obesity and extreme obesity. Physical activity plays a role in the maintenance of a healthy body weight, the loss of excess body weight, and the maintenance of successful weight loss because of its role in energy balance [11]. Increasing physical activity among US adults through informational, behavioral, and environmental evidence-based approaches is important for obesity prevention [20].

As indicated in our study, any alcohol drinking was related to a decreased risk for obesity and extreme obesity compared to no alcohol drinking. This finding was similar to the results from a prospective cohort study conducted by Wang and colleagues [21]. They concluded that normal weight middle-aged and older women who consumed a light to moderate amount of alcohol had a lower risk of becoming overweight and/or obese during 12.9 years of follow-up compared to nondrinkers. However, our finding should be interpreted with caution because our nondrinker group not only included those who never consume alcohol, but also former drinkers. The underlying mechanism for the association between obesity and alcohol consumption is complex and needs to be better understood. Studies found that some drinkers, especially female drinkers, tend to substitute alcohol for other foods without increasing total calorie intake, and lower intake of carbohydrates was related to higher levels of alcohol intake [21,22].

Similar to a cohort study conducted by Watari and colleagues [23], we found that current and former smokers had a significantly higher incidence of obesity compared to nonsmokers. However, findings from other published studies that examined the relationships between smoking and BMI or prevalence of obesity have been inconsistent $[12,24]$. Clarification of the mechanism that explains this association is of considerable interest.

\section{Study strengths and limitations}

The study's sample size, one of its strengths, was large enough to estimate incidence for subgroups and to ensure sufficient statistical power to detect differences across groups. Second, as the largest population-based telephone survey of adults in the United States, BRFSS allows us to obtain incidence estimates that represent all 50 states, the District of Columbia, and three US territories.

The findings in this report are subject to several limitations. First, our estimates are based on a cross-sectional survey rather than following people over time, and this limited our ability to distinguish people who were truly incident cases from those who had been obese in the past, but subsequently lost weight and then regained weight during the previous year (recurrent cases of obesity). We also assumed that the risk factors assessed in 2009 accurately reflected risk-factor status in 2009 , and that these risk factors did not differ between incident and recurrent cases of obesity. Second, BMIs were based on reported weight and height, and it is widely known that these estimates, particularly among people with high BMIs, are underestimates $[25,26]$. Previous studies have found, however, that recalled past weight is strongly correlated with measured weight and that self-reported weight change is reliable [27-29]. Although it is likely that biases in self-reported current and previous weights are correlated, this has not been documented, and our findings need to be confirmed by studies that include measured weights and heights. Third, the survey lacks complete dietary intake data, so we were not able to include all dietary behavioral factors or calorie intake in our modeling analyses. Fourth, the BRFSS excludes people who do not have landline 
telephones. Because adults who live in wireless-only households tend to be younger, male, Hispanic, binge drinkers, or current smokers, and have lower incomes [30], our incidence estimates may not be generalizable to the entire US population. Based on Council of American Survey and Research Organizations (CASRO) guidelines, the median response rate (percentage of all eligible people who completed interviews) in 2009 was only $52.5 \%$ (range: $37.9 \%-66.9 \%$ ), possibly resulting in biased estimates [31].

\section{Conclusions}

In conclusion, we found that the 2009 incidence of obesity was $4 \%$ per year and the incidence of extreme obesity was $0.7 \%$ per year. There were variations in the incidences of obesity and extreme obesity across sociodemographic groups and populations with certain behavioral factors. The high incidence of obesity underscores the importance of implementing effective policy and environmental intervention strategies in the general population. Given the significant differences in incidence across subgroups, it is possible that additional emphasis should be given to younger adults, women, minorities, and adults with lower education. Our study supports the use of physical activity as a prudent initial step to obesity prevention, but both environmental and policy approaches are needed to prevent weight gain.

\section{Disclaimer}

The findings and conclusions in this report are those of the authors and do not necessarily represent the official position of the Centers for Disease Control and Prevention.

\section{Author details}

'Division of Nutrition, Physical Activity, and Obesity, National Center for Chronic Disease Prevention and Health Promotion, Centers for Disease Control and Prevention, Atlanta, GA, USA. ${ }^{2}$ Division for Heart Disease and Stroke Prevention, National Center for Chronic Disease Prevention and Health Promotion, Centers for Disease Control and Prevention, Atlanta, GA, USA.

\section{Authors' contributions}

LP participated in the design of the study, performed the statistical data analyses, drafted and revised the manuscript. BS and DSF participated in the design of the study and revision of the manuscript. CG and SP participated in the revision of the manuscript. All authors read and approved the final manuscript.

\section{Competing interests}

The authors declare that they have no competing interests.

Received: 4 February 2011 Accepted: 17 October 2011

Published: 17 October 2011

\section{References}

1. Flegal KM, Carroll MD, Kuczmarski RJ, Johnson CL: Overweight and obesity in the United States: prevalence and trends, 1960-1994. Int J Obes Relat Metab Disord 1998, 22(1):39-47.
2. Flegal $\mathrm{KM}$, Carroll MD, Ogden $\mathrm{CL}$, Johnson $\mathrm{CL}$ : Prevalence and trends in obesity among US adults, 1999-2008. JAMA 2010, 303(3):235-241.

3. US Department of Health and Human Services: Healthy People 2020 Summary of Objectives. Washington, DC: US Department of Health and Human Services; 2010 [http://healthypeople.gov/2020/topicsobjectives2020/ pdfs/HP2020objectives.pdf].

4. National Heart, Lung, and Blood Institute: Clinical Guidelines on the Identification, Evaluation, and Treatment of Overweight and Obesity in Adults: The Evidence Report. Obes Res 1998, 6(Suppl 2):51S-209S.

5. US Department of Health and Human Services: The Surgeon General's Call to Action to Prevent and Decrease Obesity. Rockville, MD: US Department of Health and Human Services, US Public Health Service, Office of the Surgeon General; 2001 [http://www.surgeongeneral.gov/topics/obesity/ calltoaction/CalltoAction.pdf].

6. Finkelstein EA, Trogdon JG, Cohen JW, Dietz W: Annual medical spending attributable to obesity: payer-and service-specific estimates. Health Aff 2009, 28(5):w822-w831.

7. Centers for Disease Control and Prevention: Vital signs: state-specific prevalence of obesity among adults-United States, 2009. MMWR Morb Mortal Wkly Rep 2010, 59(Early Release):1-5.

8. Nemesure B, WU S-Y, Hennis A, Leske MC, the BES Group: Nine-year incidence of obesity and overweight in an African-origin population. Int J Obes 2008, 32(2):329-335.

9. Parikh NI, Pencina MJ, Wang TJ, Katherine J, Lanier KJ, Fox CS, D'Agostino RB, Vasan RS: Increasing trends in incidence of overweight and obesity over 5 decades. Am J Med 2007, 120(3):242-250.

10. Williamson DF, Kahn HS, Remington PL, Anda RF: The 10-year incidence of overweight and major weight gain in US adults. Arch Intern Med 1990, 150(3):665-672.

11. US Department of Health and Human Services: 2008 Physical Activity Guidelines for Americans. Washington, DC: US Department of Health and Human Services; 2008 [http://www.health.gov/paguidelines].

12. Tavani A, Negri E, La Vecchia C: Determinants of body mass index: a study from northern Italy. Int J Obes Relat Metab Disord 1994, 18(7):497-502.

13. Centers for Disease Control and Prevention: Behavioral Risk Factor Surveillance System Operational and User's Guide. Atlanta, GA: US Department of Health and Human Services, Centers for Disease Control and Prevention; 2006 [http://ftp.cdc.gov/pub/data/brfss/userguide.pdf].

14. Nelson DE, Holtzman D, Bolen J, Stanwyck CA, Mack KA: Reliability and validity of measures from the Behavioral Risk Factor Surveillance System (BRFSS). Soz Praventivmed 2001, 46(Suppl 1):S3-S42.

15. Korn EL, Graubard Bl: Analysis of Health Surveys: Wiley Series in Probability and Statistics New York: John Wiley \& Sons, Inc; 1999.

16. MCTigue KM, Garrett JM, Popkin BM: The natural history of the development of obesity in a cohort of young US adults between 1981 and 1998. Ann Intern Med 2002, 136(12):857-864.

17. Williamson DF, Kahn HS, Byers T: The 10-y incidence of obesity and major weight gain in black and white US women aged 30-55 y. Am J Clin Nutr 1991, 53(6 Suppl):1515S-1518S.

18. Milstein RA, Carlson SA, Fulton JE, Galuska DA, Zhang J, Blanck HM, Ainsworth BE: Relationships between body satisfaction and weight control practices among US adults. Medscape J Med 2008, 10(5):119.

19. Adler $\mathrm{NE}$, Stewart J: Reducing obesity: motivating action while not blaming the victim. Milbank Q 2009, 87(1):49-70.

20. US Preventive Services Task Force on Community Preventive Services: Recommendations to increase physical activity in communities. Am J Prev Med 2002, 22(4S):67-72.

21. Wang L, Lee IM, Manson JE, Buring JE, Sesso HD: Alcohol consumption, weight gain, and risk of becoming overweight in middle-aged and older women. Arch Intern Med 2010, 170(5):453-461.

22. Colditz GA, Giovannucci E, Rimm EB, Stampfer MJ, Rosner B, Speizer FE, Gordis E, Willett WC: Alcohol intake in relation to diet and obesity in women and men. Am J Clin Nutr 1991, 54(1):49-55.

23. Watari M, Uetani M, Suwazono Y, Kobayashi E, Kinouchi N, Nogawa K: A longitudinal study of the influence of smoking on the onset of obesity at a telecommunications company in Japan. Prev Med 2006 43(2):107-112.

24. Lahti-Koski M, Pietinen P, Heliövaara M, Vartiainen E: Associations of body mass index and obesity with physical activity, food choices, alcohol intake, and smoking in the 1982-1997 FINRISK Studies. Am J Clin Nutr 2002, 75(5):809-817. 
25. Merrill RM, Richardson JS: Validity of self-reported height, weight, and body mass index: findings from the National Health and Nutrition Examination Survey, 2001-2006. Prev Chronic Dis 2009, 6(4):A121.

26. Yun $S$, Zhu BP, Black W, Brownson RC: A comparison of national estimates of obesity prevalence from the behavioral risk factor surveillance system and the National Health and Nutrition Examination Survey. Int $J$ Obes 2006, 30(1):164-170.

27. French SA, Jeffery RW, Folsom AR, Williamson DF, Byers T: Weight variability in a population-based sample of older women: reliability and intercorrelation of measures. Int J Obes Relat Metab Disord 1995, 19:22-29.

28. Perry S, Byers TE, Mokdad AH, Serdula MK, Williamson DF: The validity of self reports of past body weights by U.S. adults. Epidemiology 1995, 6:61-66.

29. Nohr EA, Vaeth M, Baker JL, Sorensen TIA, Olsen J, Rasmussen KM: Combined association of prepregnancy body mass index and gestational weight gain with the outcome of pregnancy. Am J Clin Nutr 2008, 87:1750-1759.

30. Blumberg SJ, Luke JV: Wireless Substitution: Early Release of Estimates Based on Data from the National Health Interview Survey. 2010, 34 [http://www.cdc.gov/nchs/data/nhis/earlyrelease/wireless201005.pdf]

31. Centers for Disease Control and Prevention: Behavioral Risk Factor Surveillance System: 2009 Summary Data Quality Report. Atlanta, GA: U.S. Department of Health and Human Services, Centers for Disease Control and Prevention; 2010 [http://www.cdc.gov/brfss/technical_infodata/quality.htm].

doi:10.1186/1478-7954-9-56

Cite this article as: Pan et al:: Incidences of obesity and extreme obesity among US adults: findings from the 2009 Behavioral Risk Factor Surveillance System. Population Health Metrics 2011 9:56.

\section{Submit your next manuscript to BioMed Central and take full advantage of:}

- Convenient online submission

- Thorough peer review

- No space constraints or color figure charges

- Immediate publication on acceptance

- Inclusion in PubMed, CAS, Scopus and Google Scholar

- Research which is freely available for redistribution

Submit your manuscript at www.biomedcentral.com/submit 